\title{
A 5-Year Clinical Experience of Haemolysis, Elevated Liver Enzymes and Low Platelet Count (HELLP) Syndrome at a Tertiary Care Teaching Hospital in North Karnataka - A Retrospective Analysis
}

\author{
Aruna Mallangouda Biradar ${ }^{1}$, Rajasri G Yaliwal², Shreedevi Somashekar Kori³ ${ }^{3}$ Gamini B S ${ }^{4}$, Shivakumar U Pujeri ${ }^{5}$ \\ ${ }^{1}$ Department of Obstetrics and Gynaecology, Shri B.M. Patil Medical College and Hospital, BLDE (Deemed to Be \\ University), Vijayapura, Karnataka, India. ${ }^{2}$ Department of Obstetrics and Gynaecology, Shri B.M. Patil Medical \\ College and Hospital, BLDE (Deemed to Be University), Vijayapura, Karnataka, India. ${ }^{3}$ Department of Obstetrics \\ and Gynaecology, Shri B.M. Patil Medical College and Hospital, BLDE (Deemed to Be University), Vijayapura, \\ Karnataka, India. ${ }^{4}$ Department of Obstetrics and Gynaecology, Shri B.M. Patil Medical College and Hospital, BLDE \\ (Deemed to Be University), Vijayapura, Karnataka, India. ${ }^{5}$ Department of Obstetrics and Gynaecology, Shri B.M. \\ Patil Medical College and Hospital, BLDE (Deemed to Be University), Vijayapura, Karnataka, India
}

\section{ABSTRACT}

\section{BACKGROUND}

Haemolysis (H), elevated liver enzymes (EL) and low platelet count (LP) i.e., HELLP syndrome is a vaguely understood condition of pregnancy which can present with rapid onset. It is commonly associated with pre - eclampsia. HELLP is also known to manifest itself without the clinical features of pre - eclampsia. The present study aims to assess the maternal and foetal complications associated with HELLP syndrome.

\section{METHODS}

This retrospective study included all the pregnant women who developed HELLP / partial HELLP with gestational age of $\geq 28$ weeks. The variables analyzed were obstetric history, menstrual history, antenatal complications, laboratory investigations (haemolysis, ALT / AST, LDH, CBC), mode of delivery, postnatal complications, maternal outcomes and perinatal outcomes.

\section{RESULTS}

72 patients were included in the present study. The mean age of pregnant women with HELLP syndrome was $23.6 \pm 4.15$ years. The average age of gestation was 33.17 \pm 4.02 weeks. $58 \%$ patients were primigravida. As per Mississippi triple-class system $82 \%$ patients had partial HELLP, $18 \%$ had complete HELLP. $4 \%, 4 \% \& 10 \%$ patients had HELLP class I, II \& III respectively. Among the total cases, $74 \%$ patients had antepartum onset, $10 \%$ had intrapartum \& $17 \%$ postpartum onset of HELLP syndrome respectively. $65 \%$ patients delivered vaginally \& rest $35 \%$ underwent caesarean section. High risk factors such as pre - eclampsia (65 \%), eclampsia (3\%) \& previous history of HELLP (8 \%) were noted in study cases. Abruptio placentae (18 $\%)$, postpartum haemorrhage (17\%), pulmonary oedema (14\%), renal failure (14 \%) \& DIC (7 \%) were the maternal complications noted. Maternal mortality was $7 \%$. The major perinatal morbidities noted were prematurity (67 \%) \& FGR (42\%). Intrauterine death was noted in $19 \%$ babies. Neonatal intensive care (NICU) was required for $58 \%$ babies, of which $42 \%$ had respiratory distress. Neonatal death was noted in $17 \%$.

\section{CONCLUSIONS}

HELLP syndrome is a life threatening condition of pregnancy which has serious maternal and perinatal morbidities. Prompt referral, timely and appropriate interventions can save lives. Availability of Intensive Care Units (ICU) facilities, dialysis units and blood and its components along with Neonatal Intensive Care Unit (NICU) facilities can remarkably reduce the maternal and neonatal complications.

\section{KEY WORDS}

HELLP Syndrome, Preeclampsia, Maternal Mortality, Neonatal Mortality, Mississippi Triple - Class System
Corresponding Author: Dr. Rajasri G Yaliwal, Associate Professor, Department of OBG, Shri B.M. Patil Medical College and Hospital, BLDE (Deemed to Be University), Vijayapura, Karnataka, India. E-mail: ryaliwal@bldedu.ac.in

\section{DOI: $10.14260 / \mathrm{jemds} / 2020 / 644$}

How to Cite This Article:

Biradar AM, Yaliwal RG, Kori SS, et al. A 5year clinical experience of haemolysis, elevated liver enzymes and low platelet count (HELLP) syndrome at a tertiary care teaching hospital in North Karnataka - a retrospective analysis. J Evolution Med Dent Sci 2020;9(40):2938-2941, DOI: $10.14260 / \mathrm{jemds} / 2020 / 644$

Submission 15-07-2020,

Peer Review 27-08-2020,

Acceptance 02-09-2020,

Published 05-10-2020.

Copyright (c) 2020 Aruna Mallangouda Biradar, et al. This is an open access article distributed under Creative Commons Attribution License [Attribution 4.0 International (CC BY 4.0)] 


\section{BACKGROUND}

Haemolysis $(\mathrm{H})$, elevated liver enzymes (EL) and low platelet count (LP) is a group of laboratory indices which is abbreviated as HELLP syndrome. It is a vaguely understood condition of pregnancy which can present with an expeditious onset. It is commonly associated with pre - eclampsia though few cases can occur without the clinical features of pre eclampsia. ${ }^{1}$

The exact aetiology remains unknown. The disease process is said to start from the time of implantation. There is incomplete invasion of the trophoblastic cells into the decidua. The defective maternal spiral arteries remodelling in turn results in activation of the coagulation system. This further results in vascular ischemia, fibrin deposits, vasospasm and activation of clotting cascade. This triggers the release of angiogenic factors which in turn cause hypertension and proteinuria. ${ }^{2}$ Microvasular injury can cause multiple organs to be affected. In the Liver, raised liver enzymes are noticed. ${ }^{3}$

Another theory is that the foetus is the cause of the maternal disease. Abnormal oxidation of the fatty acids in the foetus and the transfer of these metabolites to the mother can cause the vascular defects and further multiorgan involvement. ${ }^{4}$

The diagnosis of HELLP syndrome is based on laboratory findings. Clinical suspicion of the disease is illusive as the symptoms of nausea and vomiting, headache or malaise are non - specific and manifest in other conditions such as viral hepatitis or acute fatty liver of pregnancy. Some patients will present with epigastric pain or right hypochondriac pain which is an unfavourable symptom. ${ }^{5}$

Laboratory diagnosis of HELLP syndrome is done on the following laboratory criteria. ${ }^{2}$

1. Haemolysis is defined by abnormal peripheral blood smear and increased bilirubin levels $(1.2 \mathrm{mg} / \mathrm{dL}$ or more); Haemolysis characterised by microangiopathic haemolytic anaemia. This is diagnosed by the presence of histocytes and Burr cells in the peripheral smear.

2. Elevated liver enzymes, defined by aspartate aminotransferase (AST) of $70 \mathrm{IU} / \mathrm{L}$ or more and lactate dehydrogenase (LDH) above $600 \mathrm{U} / \mathrm{L}$

3. Decreased platelet count $\left(<100,000 \mathrm{~mm}^{3}\right)$. Increased serum lactate dehydrogenase level, decreased haptoglobin concentration and the presence of unconjugated bilirubin (>1.2 mg / $100 \mathrm{~mL}$ ) all shows sign of haemolysis. Liver enzyme elevation shows liver involvement and also haemolysis. The activated platelets adhere to the damaged vascular endothelial cells which causes the circulating count of platelets to decrease.

It is associated with serious maternal morbidity, as renal failure, disseminated intravascular coagulation (DIC), consumptive coagulopathy, sub capsular liver haematoma, abruption-placenta, pulmonary and cerebral edema, hypovolemic shock and subsequent severe postpartum bleeding. Prematurity, foetal growth retardation (FGR), thrombocytopenia and perinatal death are the most common foetal complications. ${ }^{6}$ This condition is often underdiagnosed.

The aim of treatment of HELLP syndrome patients is to terminate pregnancy at 34 weeks or to terminate the pregnancy in view of presence of maternal complications such as multiorgan dysfunction, non - reassuring foetal conditions or other obstetric catastrophies like placental abruption. ${ }^{7}$

The present study aims to evaluate the maternal and foetal outcomes in pregnancies with HELLP syndrome.

\section{METHODS}

The study was conducted in the Department of Obstetrics and Gynaecology, Shri. B.M. Patil Medical College Hospital and Research Centre, BLDE (Deemed to Be) University, Vijayapura, Karnataka, India from April $1^{\text {st }} 2015$ to $31^{\text {st }}$ March 2020. The study had been approved by the Institutional ethics committee with reference number BLDE (DU) / IEC / 410 / 2019-20.

All pregnant women who developed HELLP / partial HELLP with gestational age $\geq 28$ weeks were included in the study. Woman with other medical disorders like cholecystitis, viral hepatitis were excluded as these patients will have deranged hepatic parameters that confound the findings of HELLP syndrome. As period of viability in India is taken as 28 weeks, hence the cases with gestational age $\leq 28$ weeks were excluded.

The diagnosis of HELLP syndrome was made when the following laboratory investigation were present, haemolysis, abnormal liver enzymes and low platelets. (Table 1$)^{8}$

Maternal outcomes were measured in terms of age of mother, parity, period of gestation, severity of preeclampsia, eclampsia, class of HELLP syndrome, mode of delivery, need for blood and its components, pulmonary edema, acute renal failure, abruption placenta, disseminated intravascular coagulation, postpartum haemorrhage and maternal mortality. Perinatal outcome were measured in terms of prematurity, FGR, intrauterine foetal demise (IUD), birth asphyxia, NICU admission and early neonatal death. After complete stabilization patients were discharged.

\section{Statistical Analysis}

Data was collected \& analyzed. Statistical analysis. All characteristics were summarized descriptively for continuous variables; the summary statistics of mean \pm standard deviation (SD) were used. For categorical data, the number and percentage were used in the data summaries and diagrammatic presentation. Data were analyzed using SPSS software v.23.0.

\section{RESULTS}

72 patients were included in the present study. The average maternal age of the patients was $23.6 \pm 4.15$ years. The mean gestational age was $33.17 \pm 4.02$ weeks; ranging between 29 38 weeks? Mean parity of patients was $1.82 \pm 1.01$. $58 \%$ patients were primigravida. The mean systolic blood pressure (SBP) was $154 \pm 22.9 \mathrm{mmHg} \&$ diastolic blood pressure (DBP) was $102.1 \pm 21.4 \mathrm{mmHg}$. Mean Proteinuria was $2.3 \pm 1.2$ (semi quantitative analysis) (Table 2).

As per Mississippi triple - class system $82 \%$ patients had partial HELLP syndrome and $18 \%$ had complete HELLP syndrome. The HELLP syndrome was classified into three 
classes depending upon platelet count; AST or ALT and LDH levels. In our study $4 \%$ of the patients were in class I and II each and $10 \%$ of the patients were in class III of HELLP syndrome. Antepartum onset was observed in $74 \%$ of the patients, another $10 \%$ had intrapartum onset and $17 \%$ had postpartum onset of the disease. In our study, $65 \%$ patients delivered vaginally and $35 \%$ underwent cesarean section. High risk factors such as pre - eclampsia (65\%), eclampsia (3 $\%$ ) \& previous history of HELLP syndrome (8 \%) were noted in study patients (Table 3). Abruptio placentae (18\%), postpartum haemorrhage (17\%), and pulmonary edema (14 $\%)$, acute kidney injury (AKI) (14\%), DIC (7 \%) and maternal mortality $(7 \%)$ were the maternal complications observed in the present study. (Table 4)

\begin{tabular}{|cccc|}
\hline HELLP Class & $\begin{array}{c}\text { Platelet Count } \\
\text { (in } \boldsymbol{\mu L} \text { ) } \\
1\end{array}$ & $\begin{array}{c}\text { AST or ALT } \\
\text { (in IU / L) }\end{array}$ & $\begin{array}{c}\text { Total LDH } \\
\text { (in IU / L) }\end{array}$ \\
2 & $\begin{array}{c}250,000 \\
1,00,000\end{array}$ & $\geq 70$ & $\geq 600$ \\
3 & $>1,00,000 \& \leq$ & $\geq 70$ & $\geq 600$ \\
& $1,50,000$ & $\geq 40$ & $\geq 600$ \\
Partial HELLP & Presence of Severe Preeclampsia - Eclampsia in Association \\
Syndrome & with two of three \\
\hline \multicolumn{3}{|c|}{ Table 1. HELLP Syndrome - Mississippi Triple - Class System. ${ }^{4}$} \\
\hline HELLP: Haemolysis, Elevated Liver enzymes, Low Platelet count, AST: \\
aspartate aminotransferase, ALT: alanine aminotransferase, LDH: lactate \\
dehydrogenase.
\end{tabular}

\begin{tabular}{|cc|}
\hline Characteristic & Mean ( \pm 2SD) \\
Maternal Age (Years) & $23.6 \pm 4.15$ \\
Gestational Age (Weeks) & $33.17 \pm 4.02$ \\
Parity & $1.82 \pm 1.01$ \\
Systolic BP (mmHg) & $154 \pm 22.9$ \\
Diastolic BP (mmHg) & $102.1 \pm 21.4$ \\
Proteinuria (1+ to 4+) & $2.3 \pm 1.2$ \\
\hline Table 2. Demographic and Clinical Characteristics \\
\hline
\end{tabular}

\begin{tabular}{|c|c|c|c|}
\hline Parameters & Partial HELLP & HELLP & Total \\
\hline \multicolumn{4}{|c|}{ Mississippi Classification } \\
\hline No. of Cases & $59(82 \%)$ & $13(18 \%)$ & $72(100 \%)$ \\
\hline HELLP Class I & & $3(4 \%)$ & \\
\hline HELLP Class II & & $3(4 \%)$ & \\
\hline HELLP class III & & $7(10 \%)$ & \\
\hline \multicolumn{4}{|c|}{ Time of Onset } \\
\hline Antepartum & $45(63 \%)$ & $8(11 \%)$ & $53(74 \%)$ \\
\hline Intrapartum & $6(8 \%)$ & $1(1 \%)$ & $7(10 \%)$ \\
\hline Postpartum & $8(11 \%)$ & $4(6 \%)$ & $12(17 \%)$ \\
\hline \multicolumn{4}{|c|}{ Mode of Delivery } \\
\hline Vaginal Delivery & $39(54 \%)$ & $8(11 \%)$ & $47(65 \%)$ \\
\hline Caesarean Delivery & $20(28 \%)$ & $5(7 \%)$ & $25(35 \%)$ \\
\hline \multicolumn{4}{|c|}{ High Risk Factors } \\
\hline Pre - Eclampsia & $40(56 \%)$ & $7(10 \%)$ & $47(65 \%)$ \\
\hline Eclampsia & $1(1 \%)$ & $1(1 \%)$ & $2(3 \%)$ \\
\hline $\begin{array}{c}\text { Previous History of } \\
\text { HELLP }\end{array}$ & $2(3 \%)$ & $4(6 \%)$ & $6(8 \%)$ \\
\hline
\end{tabular}

\begin{tabular}{|cccc|}
\hline $\begin{array}{c}\text { Maternal } \\
\text { Complications }\end{array}$ & Partial HELLP & $\begin{array}{c}\text { No. of Cases (\%) } \\
\text { HELLP }\end{array}$ & Total \\
Postpartum Haemorrhage & $8(11 \%)$ & $4(6 \%)$ & $12(17 \%)$ \\
DIC & $2(3 \%)$ & $3(4 \%)$ & $5(7 \%)$ \\
Abruptio Placentae & $11(15 \%)$ & $2(3 \%)$ & $13(18 \%)$ \\
Pulmonary Edema & $5(7 \%)$ & $5(7 \%)$ & $10(14 \%)$ \\
Acute Kidney Injury & $6(8 \%)$ & $4(6 \%)$ & $10(14 \%)$ \\
Maternal Death & $2(3 \%)$ & $3(4 \%)$ & $5(7 \%)$ \\
\hline \multicolumn{4}{c}{ Table 4. Maternal Complications } \\
\hline
\end{tabular}

In terms of perinatal morbidity, prematurity (67\%) \& FGR $(42 \%)$ were major outcomes. Intrauterine death was noted in $19 \%$ babies. Post - delivery NICU admission was required in
$58 \%$ babies and among them $42 \%$ had respiratory distress. Early neonatal death was observed in $17 \%$ of the babies (Table 5).

\begin{tabular}{|cccc|}
\hline $\begin{array}{c}\text { Perinatal } \\
\text { Complications }\end{array}$ & Partial HELLP & HELLP & Total \\
Prematurity & $39(54 \%)$ & $9(13 \%)$ & $48(67 \%)$ \\
FGR & $25(35 \%)$ & $5(7 \%)$ & $30(42 \%)$ \\
Respiratory distress & $13(18 \%)$ & $3(4 \%)$ & $16(22 \%)$ \\
IUD & $11(15 \%)$ & $3(4 \%)$ & $14(19 \%)$ \\
NICU admission & $35(49 \%)$ & $7(10 \%)$ & $42(58 \%)$ \\
Early neonatal death & $8(11 \%)$ & $4(6 \%)$ & $12(17 \%)$ \\
\hline \multicolumn{4}{c|}{ Table 5. Perinatal Complications } \\
\hline
\end{tabular}

\section{DISCUSSION}

HELLP syndrome is a devastating maternal complication. Patients are usually diagnosed in late stages with multiorgan dysfunction. Aggressive treatment with multispecialty approach is required in many of the cases. Facilities like ICU, blood bank with component therapy and round the clock services of obstetricians, neonatologists and intensivists are required to treat such cases. In $4-12 \%$ of the cases of severe pre - eclampsia, HELLP syndrome has been diagnosed. It causes high percentage of maternal (24\%) and perinatal (up to $40 \%$ ) mortalities even with timely decision of delivery. ${ }^{9}$

The chance of pre - eclamptic women developing HELLP is $0.5-0.9 \%$. The presentation of the syndrome may be complete wherein all the three components of the HELLP manifest, or partial where at least two of the three components manifest.10 presentation of the disease has seen to be acute and often dramatic. Hypertension and proteinuria is seen in 10-20\% of the cases with HELLP. 5 The clinical profile of preeclampsia can affect the mother by causing multiorgan disorders and can affect the foetus by causing foetal growth restriction. ${ }^{11}$

Mean maternal age in our study was $23.6 \pm 4.15$ years. Various other studies conducted in India observed that the mean maternal age was $27.31 \pm 5.0$ years ${ }^{11}$ and $24.25 \pm 3.05 .12$ The mean gestational age at presentation in our study was $33.17 \pm 4.02$, in other Indian studies, the mean gestational age was $32.89 \pm 2.66$ weeks $^{12}, 36.34 \pm 3.75$ weeks, ${ }^{13} 36.06 \pm 3.50$ weeks by. ${ }^{14}$ In the present study, $58 \%$ patients were primigravida, which was comparable with a study done in south India (60.7 \% ). ${ }^{15}$ In another study in India showed 63.64 $\%$ were primigravida. ${ }^{16}$

In the present study, $65 \%$ delivered vaginally and $35 \%$ underwent cesarean section. The results are comparable with a study done in Kolkata, India, where in $27.27 \%$ of the patients had vaginal delivery and $72.72 \%$ underwent cesarean section. ${ }^{17}$ Hypertensive disorders of pregnancy were the most common risk factor noted in $68 \%$ patients in our study. Two (3\%) patients had eclampsia, which is far less than the study conducted in Mumbai, India where in $23 \%$ had eclampsia with HELLP syndrome. ${ }^{18}$

Abruptio placentae (18\%), postpartum haemorrhage (17 $\%)$, and pulmonary edema (14\%), acute kidney injury (AKI) (14\%), DIC (7\%) and maternal mortality (7\%) were the maternal complications observed in the present study. In a study conducted in Andhra Pradesh ${ }^{17}$ maternal mortality was higher than that observed in our study $61.66 \%$. In a study conducted in Kerala, out of 55 cases with HELLP syndrome, no maternal deaths were observed ${ }^{18}$ and the study had reported 
that most maternal complications were due to DIC and Abruptio placenta. A study conducted in Delhi ${ }^{12}$ reported maternal mortality of $12.5 \%$ due to pulmonary edema, liver haematoma and DIC. Another study in Andhra Pradesh reported that the maternal mortality in their study was 4.5 $\% .{ }^{14}$

The maternal mortality in HELLP syndrome averages from 1 to $25 \%$. The leading causes of maternal mortality in HELLP are sepsis, disseminated intravascular coagulation (DIC), acute respiratory distress syndrome, liver failure, acute kidney injury, stroke or cardiopulmonary arrest.

In present study NICU admission was required in $58 \%$ of the babies and among them $42 \%$ had respiratory distress. Early neonatal death was noted in $17 \%$ in the present study. A study done in Kerala reported that prematurity with FGR accounts for most common complications among HELLP syndrome patients. ${ }^{18}$ Perinatal morbidity was $46.6 \%$ in a study done in Andhra Pradesh. ${ }^{17}$ A study done in Delhi reported a perinatal mortality of $45.8 \%$ cause due to prematurity and FGR. ${ }^{12}$ Another study in Andhra Pradesh showed reported prematurity as the major cause for perinatal mortality of $24 \% .{ }^{13}$

Adverse maternal and perinatal outcomes stresses upon the need for early recognition of the disease with prompt antenatal care (ANC) registration, regular antenatal follow up and monitoring of clinical symptoms and laboratory parameters.

In HELLP syndrome, it has been noticed that there is no correlation between the level of hypertension and the severity of the disease. The biochemical laboratory values carry more importance in the diagnosis. The hypertensive complications are considered as a major risk factor for recurrence and may also be responsible for adverse outcomes like FGR and placental abruption.

\section{CONCLUSIONS}

HELLP syndrome is a serious complication of pregnancy. A standardized protocol to diagnose and manage HELLP syndrome is the need of the hour. Prompt referral, timely and appropriate intervention can save lives. Availability of intensive care units (ICU), dialysis units and blood and its components along with NICU facilities can significantly improve the maternal and neonatal outcomes.

Financial or Other Competing Interests: None.

\section{REFERENCES}

[1] Bang NO, Satia MN, Poonia S. Obstetric and neonatal outcome in pregnancies complicated by haemolysis elevated liver enzymes low platelet count syndrome at a tertiary care centre in India. Int J Reprod Contracept Obstet Gynecol 2017;5(7):2407-12.
[2] Joern H, Funk A, Rath W. Doppler sonographic findings for hypertension in pregnancy and HELLP syndrome. Journal of Perinatal Medicine 1999;27(5):388-94.

[3] Andraweera PH, Dekker GA, Roberts CT. The vascular endothelial growth factor family in adverse pregnancy outcomes. Hum Reprod Update 2012;18(4):436-57.

[4] Shekhawat PS, Matern D, Strauss AW. Foetal fatty acid oxidation disorders, their effect on maternal health and neonatal outcome: impact of expanded newborn screening on their diagnosis and management. Pediatr Res 2005;57(5 Pt 2):78R-86R.

[5] Sibai BM. Diagnosis, controversies, and management of the syndrome of haemolysis, elevated liver enzymes, and low platelet count. Obstet Gynecol 2004;103(5 Pt 1):98191.

[6] Mihu D, Costin N, Mihu CM, et al. HELLP syndrome - a multisystemic disorder. J Gastrointestin Liver Dis 2007;16(4):419-24.

[7] Bearelly D, Hammoud GM, Koontz G, Merrill DC, Ibdah J. Preeclampsia-induced liver disease and HELLP syndrome In: Ibdah J. A., ed. Maternal Liver Disease. $1^{\text {st }}$ edn. Austin, TX: Landes Bioscience 2012;74-91.

[8] Martin JN, Brewer JM, Wallace K, et al. Hellp syndrome and composite major maternal morbidity: importance of Mississippi classification system. J Matern Foetal Neonatal Med 2013;26(12):1201-6.

[9] Jagia M, Taqi S, Hanafi $M$, et al. Thrombocytopeniaassociated multiple organ failure or severe haemolysis, elevated liver enzymes, low platelet count in a postpartum case. Indian J Anaesth 2013;57(1):62-5.

[10] Haram K, Svendsen E, Abildgaard U. The HELLP syndrome: clinical issues and management. A review. BMC Pregnancy Childbirth 2009;9:8.

[11] Sibai B, Dekker G, Kupferminc M. Pre-eclampsia. Lancet 2005;365(9461):785-99.

[12] Chawla S, Marwaha A, Agarwal R. HELLP or help: a real challenge. J Obstet Gynaecol India 2015;65(3):172-5.

[13] Kumari S, Bhavani, Himabindu, et al. Clinical study on HELLP syndrome-maternal and perinatal outcome. IOSRJDMS 2016;15(1):71-6.

[14] Kaur AP, Saini AS, Dhillon SPS. HELLP syndrome associated with moderate to severe preeclampsia eclampsia. J Obstet Gynecol India 2003;53(2):165-9.

[15] Boopathi A, Kushtagi P. HELLP syndrome in a Government District Hospital on the west coast in South India. Int J Biomed Res 2014;5(7):439-42.

[16] Rakshit A, Lahiri S, Biswas SC, et al. A study to detect HELLP syndrome and partial HELLP syndrome among preeclamptic mothers and their impact on foetomaternal outcome. Al Ameen J Med Sci 2014;7(1):20-5.

[17] Kota LN, Garikapati K, Kodey PD, et al. Study on HELLP syndrome-maternal and perinatal outcome. Int J Reprod Contracept Obstet Gynaecol 2017;6(2):714-9.

[18] Malleswara A, Kanta SR, Shivappa P. A clinical study of HELLP syndrome and its outcome in a tertiary health care system. Int J Reprod Contracept Obstet Gynecol 2016;5(12):4196-9. 